\title{
Prediction of resistance coefficients in ship hydrodynamics
}

The conference MARINE2007 was held in June 2007 in Barcelona, Spain, as the second in a series of thematic conferences, Computational Methods in Marine Engineering, organized by the European Community on Computational Methods in Applied Sciences (ECCOMAS) starting in 2005. At this event, a special session was dedicated to "Prediction of resistance coefficients in ship hydrodynamics". The following papers are expanded versions of three of the papers presented at the conference.

Luís Eça and Michel Visonneau, Organizers Yoshiaki Kodama, Editor-in-Chief, JMST
1. Eça L, Hoekstra M (2008) On the numerical accuracy of the prediction of resistance coefficients in ship stern flow calculations. Mar Sci Technol. doi: 10.1007/ s00773-008-0003-8

2. Di Mascio A, Broglia R, Muscari R (2008) Prediction of hydrodynamic coefficients of ship hulls by highorder Godunov-type methods. Mar Sci Technol. doi: 10.1007/s00773-008-0021-6

3. Toxopeus SL (2008) Deriving mathematical manoeuvring models for bare ship hulls using viscous flow calculations. Mar Sci Technol. doi: 10.1007/s00773008-0002-9
L. Eça $(\bowtie)$

Instituto Superior Tecnico, Lisbon, Portugal

e-mail: eca@marine.ist.utl.pt

M. Visonneau

Fluid Mechanics Laboratory, Ecole Centrale de Nantes,

Nantes, France

e-mail: michel.visonneau@ec-nantes.fr

Y. Kodama

National Maritime Research Institute, Tokyo, Japan

e-mail: kodama@nmri.go.jp 